\title{
ROLAND BARTHES Y LA FRASE ETERNA DE FLAUBERT Andreas Kurz*
}

En "Flaubert et la phrase", uno de los Nuevos ensayos críticos agregados a Le degré zéro de l'écriture, Roland Barthes esboza, mejor dicho, insinúa, una poética de las correcciones. Ésta se hace pensable gracias a que, en la gran literatura francesa del siglo XIX, el valor literario empezara a recaer sobre la frase, es decir, la palabra dejara de ser la pieza distintiva en el juego literario para transferir su lugar a la oración, que sería el nuevo campo de experimentación para los autores tanto de realismo-naturalismo, como de simbolismo-decadentismo. Sintaxis en lugar de morfología, aunque se trata de una poco lingüística, me atrevería a decir, cuasi metafísica.

Flaubert, el gran maníaco de la literatura francesa, ilustra mejor que

* Departamento de Filosofía y Letras, Universidad de Guanajuato. nadie las teorías de Barthes. Hay dos campos para el corrector empedernido: 1) Se corrigen palabras, se tacha o se sustituye. El procedimiento se basa en el principio de la metáfora - una cosa por otra- y es, por razones matemáticas, limitado. 2) Se corrige la oración, es decir, se sigue la lógica de la metonimia, se comprime o se amplía la frase. En el segundo caso se trata, de nuevo por razones matemáticas, de un quehacer ilimitado. ${ }^{1}$ Flaubert sigue este modelo, mas logra convertir lo limitado en ilimitado. En los manuscritos conocidos del autor de Madame Bovary destacan dos manías. Flaubert procura evitar las repeticiones de palabras,

${ }^{1}$ Roland Barthes, "Flaubert et la phrase", en Le degré zéro de l'écriture suivi de Nouveaux essais critiques, 1972, París, Éditions du Seuil, p. 131-40, aquí: p. 133 s. 
en sí una tarea limitada. No obstante, el escritor se da cuenta de que, eliminando una repetición en un lugar específico, genera una repetición nueva en otro lugar, y así sucesivamente: una verdadera puesta en abismo estilística. Por otro lado, Flaubert se preocupa aún más por las conexiones entre las frases, y se encuentra ante una paradoja: el novelista es capaz de construir oraciones perfectas, pero precisamente la perfección es el problema. Una frase perfecta no puede conectarse con la siguiente, si no quiere renunciar a su perfección. Por ende, hay que destruir, o evitar de antemano, la perfección para que el texto pueda fluir y sus partes puedan eslabonarse. En otras palabras: se aspira a la armonía del texto que podría lograrse gracias a una deliberada mutilación de la frase. Barthes formula la paradoja de manera concisa: la oración es un objeto, encerrado en sí mismo, pero siempre abierto hacia la siguiente oración. La oración, por ende, es eterna, ninguna oración puede, dicho propiamente, terminar, sino sólo constituye un fragmento arbitrariamente escogido de La Oración. "Para Flaubert, la frase es a la vez una unidad de estilo, una unidad de trabajo y una unidad de vida." ${ }^{2}$ La frase, entonces, llega a

${ }^{2}$ Ibidem, p. 137: Pour Flaubert, la phrase est à la fois une unité de style, une unité de travail et une unité de vie. ser una auténtica religión, la metafísica del materialista y ateo Gustave Flaubert. Sobra decir que de esta constelación se desprende la agobiante responsabilidad del escritor, el valor desmesurado que Flaubert otorga al arte, que equivale al existir. La selección de los fragmentos de la oración eterna tiene consecuencias a veces no previsibles para el autor. El novelista que, como Flaubert, pretende controlar el proceso, a fuerza tendrá que corregir y volver a corregir. La publicación del texto, finalmente, se presenta como un acto violento que interrumpe el verdadero proceso creativo que se agota en la corrección perenne. De esta manera, se ofrecen dos explicaciones para la manía laboral de Flaubert. 1) En la superficie el burgués Flaubert, quien odia a la burguesía, pero es consciente de que él mismo es burgués, transforma la literatura en trabajo, en el más arduo de todos, para, de este modo, darle el valor utilitario que exige la ética laboral burguesa. 2) En lo profundo -lo que Barthes 1lamaría probablemente estructura- tal actitud se justifica por la creencia metafísica y elitista en la frase eterna que impide el éxito comercial y crítico de los textos flaubertianos, es decir, se genera un círculo vicioso formado por una ética burguesa que, en el acto, se corrige por una estética radicalmente anti-burguesa. 
En El grado cero, Barthes se había adelantado a esta explicación del 'caso Flaubert'. Como es sabido, el crítico trata de analizar el cambio de paradigma literario que caracteriza la transición entre literatura clásica y realismo-naturalismo-simbolismo. El meollo de tal cambio es decisivo para toda la obra de Barthes: la literatura refiere a algo que es forma, signo, estilo, es decir, la literatura refiere a sí misma. ${ }^{3} \mathrm{La}$ lengua (langue) se superpone como fenómeno a cualquier acto de escribir. ${ }^{4}$ Sobra decir que escribir también puede ser pintar, componer, actuar, etc. Ningún acto de escribir, sin embargo, alcanza la langue. Por ende, escribir siempre significa transgredir, aunque la transgresión, en este caso, está condenada al fracaso, ya que sólo puede basarse en una copia de un fenómeno preestablecido, brumoso y evasivo. La realidad perceptible es una copia de este fenómeno, la escritura una copia de la copia. Queda patente, de paso, el misticismo del estructuralista Barthes.

En $S / Z$, su brillante análisis de Sarrasine, el cuento de Balzac, Barthes concreta su postura de Le degré zéro. Langue y langage ahora forman el "système integral du sens" (sistema integral del sentido) que, curiosa-

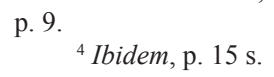
p. 9.

${ }^{4}$ Ibidem, p. 15 s.

${ }^{3}$ Roland Barthes, Le degré zéro de l'écriture, mente, tiene la función de confundir, "désystematizer", los sentidos secundarios. ${ }^{5}$ La literatura intenta una transgresión, un acercamiento al sistema langue, pero sólo alcanza una copia anterior. Su realismo -o su realidad-, por ende, es un espejismo. La frase con su "bruit régulier", la sintaxis "toute naturelle" con su sujeto y sus complementos bien ordenados, produce, en el caso de Sarrasine, una fiesta en un hotel que se ubica en un barrio concreto. Mas lo concreto se desvanece cuando se relaciona con su fondo que, hay que repetirlo, no es ningún original, sino una copia cualquiera. Le degré zéro y $S / Z$ expresan, en este caso, la misma idea: la oración eterna, cuyos fragmentos arbitrariamente producidos constituyen el texto literario, sólo es un reflejo del fenómeno inalcanzable que podría llamarse lengua, o lenguaje, o "sencillamente" la realidad como conjunto indescifrable de signos. Barthes resume el proceso en $S / Z$ :

De este modo, el realismo (bastante mal nombrado, en todo caso tan mal interpretado) consiste no en copiar lo real, sino en copiar una copia (pintada) de lo real: ese famoso real es remitido aún más lejos, como bajo el efecto de un

${ }^{5}$ Roland Barthes, $S / Z, 1970$, París, Éditions du Seuil, p. 27. 
miedo que prohibiría el contacto directo con él, es diferenciado o, por lo menos, tocado a través de una envoltura terrosa que lo diluye antes de que sea sometido a la palabra: código sobre código, es decir, el realismo. ${ }^{6}$

La frase tiene que cerrarse, tiene que concluir, aunque, ya lo sabemos, no existe ninguna conclusión auténtica para la frase; tiene que terminar para que el mundo pueda surgir, 'ser adjetivado', escribe Barthes. ${ }^{7}$ Se entiende que no se trata de ningún mundo real, sino sólo de un espejismo más cuya función principal sería oponerse al pavor ante la no-existencia, ante el horror vacui barroco. La frase funciona como un strip-tease; parte por parte puede ser sumamente estético y placentero, aunque también decididamente abominable, pero nunca se revela el todo: acceso denegado. Barthes lo expresa de manera no exenta de erotismo estructuralista:

La frase nunca puede constituir un total; los sentidos pueden engra-

${ }^{6}$ Ibidem, p. 56: Ainsi le réalisme (bien mal nommé, en tout cas souvent mal interprété) consiste, non à copier le réel, mais à copier une copie (peinte) du réel: ce fameux réel, comme sous l'effet d'une peur qui interdirait de le toucher directement, est remis plus loin, différé, ou du moins saisi à travers la gangue picturale dont on l'enduit avant de le soumettre à la parole: code sur code, dit le réalisme.

${ }^{7}$ Ibidem, p. 76. narse, mas no sumarse: el total y la suma son, para el lenguaje, tierras prometidas, entrevistas al final de la enumeración, pero cuando esta enumeración termine, ningún rasgo puede parecérsele -0 , si este rasgo se produce, sólo se agrega a los otros. Lo mismo vale para la belleza: sólo puede ser tautológica (afirmada bajo el mismo nombre de la belleza) o analítica (si se examinan sus predicados), nunca sintética. $^{8}$

Sin duda, una de las adaptaciones literarias más logradas -consciente o inconsciente, no importa en lo más mínimo- del principio de la frase eterna y sus fragmentos revelados se encuentra en Midnight's Children, obra maestra de Salman Rushdie. Aadam Aziz, fundador de una estirpe, se casará con Naseem. Conoce a su prometida como médico. La tiene que curar de una enfermedad del estómago. El pudor impide que Aadam vea a la joven de cuerpo completo. Sólo se le revela a través de un

${ }^{8}$ Ibidem, p. 110: La phrase ne peut jamais constituer un total; les sens peuvent s'égrener, non s'additionner: le total, la somme sont pour le langage des terres promises, entrevues au bout de l'énumération, mais cette énumération accomplie, aucun trait ne peut la rassembler-ou, si ce trait est produit, il ne fair que s'ajouter encore aux autres. Ainsi de la beauté: elle ne peut être que tautologique (affirmée sous le nom même de beauté) ou analytique (si l'on parcourt ses prédicats), jamais synthétique. 
agujero estratégicamente aplicado en una sábana, la parte afectada de su cuerpo. El estómago se cura, pero misteriosamente aparecen nuevas enfermedades que permiten al doctor conocer la anatomía de Naseem parte por parte, pero nunca el todo. "Así, gradualmente el doctor Aziz llegó a tener la imagen completa de Naseem en su mente, un collage de partes, respectivamente inspeccionadas, que encajaba con dificultad. Este fantasma de una mujer fraccionada comenzó a obsesionarlo, y no sólo en sus sueños." ${ }^{\prime 9}$ No conoce la cara que podría otorgar la individualidad, la ilusión del todo. Aadam y Naseem se casan; naturalmente el matrimonio es un fracaso. Los fragmentos engañaron, no representaban ninguna realidad, sino sólo una copia que, a la postre, resulta decepcionante. La arbitrariedad del intento de reflejar una realidad, la absoluta ineficiencia de la mímesis, son obvias en este episodio. Las oraciones de la literatura son fragmentos, se deben completar para vencer el espanto, pero probablemente el engañoso cierre de la frase produce un nuevo espanto.

Sorprendentemente, los principios lingüísticos propuestos por

${ }^{9}$ Salman Rushdie, Midnight's Children, 1995, Londres, Vintage, p. 25: So gradually Doctor Aziz came to have a Picture of Naseem in his mind, a badly-fitting collage of her severally-inspected parts. This phantasm of a partitioned woman began to haunt him, and not only in his dreams.
Barthes encuentran su equivalente en las ciencias exactas, sobre todo en la biología moderna y su re-interpretación de la teoría de la evolución. La naturaleza, según los científicos, no se rige por ningún principio ordenador, es caótica, es arbitraria; opera según el esquema de la bricolage. Dispone de cierta cantidad de material, aunque no tiene, de manera efectiva, acceso a este material: langue / langage en Barthes. El azar ciego decide qué material se usa para producir algo; el resultado no es previsible, podría ser cualquier cosa. La naturaleza no opera como un ingeniero, no puede basarse en ningún plan. Junta A y B, casualmente a su alcance, y a ver qué sale. No necesariamente sale C... La realidad se desvanece de este modo como producto de una casualidad espantosa. Alguna realidad tenía que producirse (es decir: cerrar la frase), pero es un resultado posible entre una infinitud..$^{10}$ Habla la ciencia exacta, la biología, no la mística, y tampoco Borges. Se deduce claramente la posibilidad de $n$ mundos posibles que podrían existir paralelamente. Los científicos experimentan al azar, hacen un bricolage, igual que la naturaleza. Si en lugar del experimento $x$ hubieran hecho el experimento $y$, el mundo como lo conocemos sería

${ }^{10}$ François Jacob, El juego de lo posible, 2005, México, FCE, cap. II, "El bricolage de la evolución”, trad. Lizbeth Sagols, p. 47-73. 
muy diferente, no sería $z$, sería irreconocible e inexpresable, por ende, irreal.

Flaubert, uno de los escritores menos realistas que puedan concebirse, parece darse cuenta de tal inexpresabilidad, y renuncia, en Bouvard et Pécuchet, su última novela, a la ilusión de conocimiento; parece aceptar la futilidad de sus propios intentos desesperados de captar la realidad mediante la escritura. Es lógico que perciba la elaboración de Bouvard et Pécuchet como una tortura dolorosa, no sólo por los miles de libros leídos para documentarse, sino también porque implica el fracaso definitivo de literatura, ciencia y razón, los tres móviles de su existencia. Escribe a Iván Turguéniev, el 1 de junio de 1874: "Pero leo tanto (por mi libro) que mis pobres ojos comienzan a cansarse. Habría que saberlo todo para este puñetero libro", y el 12 de enero de 1878: "iQué pesado es este libraco! ¿Tendré bastantes fuerzas para continuarlo? Hay que estar loco para haberse metido en esto. Sin embargo...". ${ }^{11}$ Es muy significativo el sin embargo con puntos suspensivos. Flaubert sabe que el libro será, si lo termina, un fracaso para críticos y público.

${ }^{11}$ Gustave Flaubert e Iván Turguéniev, Correspondencia, 1992, Madrid, Mondadori, ed. Alexandre Zviguilsky, trad. Danielle Lacascade, p. 153 y 250 .
Sabe también que la tarea es poco menos que interminable, mas está seguro de que vale la pena. Flaubert no puede concluir la novela, muere literalmente a causa de ella. Aun así queda claro que Bouvard y Pécuchet, estos dos bobos tan simpáticos, descubrirán, por supuesto sin buscarlo, el mecanismo de la bricolage de la biología moderna y el principio de la frase eterna descrita por Barthes. No hay conocimiento, la exactitud de ciencia y técnica es ilusoria, un engaño más. Estudian cientos de libros de las materias más diversas y tienen que darse cuenta de que las tesis científicas no son comprobables, que sólo hay contradicciones, excepciones y excepciones de la excepción. Se resignan y regresan a su antiguo oficio de copistas. Conocer significa copiar lo que ya está escrito, lo que, de su parte, ya es una copia de un fenómeno inalcanzable para científicos, artistas, pensadores y escritores. Se dan cuenta de este dilema, igual que su amo Flaubert, porque lo leen 'todo'. La decisión, entonces, a favor de un sistema específico, de una 'verdad', es arbitraria y accidental, por ende no puede ser ni real, ni verdadera. Flaubert proyecta un final 'feliz' para sus dos héroes. Fracasado el último proyecto-rousseauniano-de educar a un hijo adoptivo, reencuentran la tranquilidad sentados en su escritorio, pluma en mano, un libro, no 
importa cuál, a su alcance para ser copiado fielmente. ${ }^{12}$ No se trata de la copia al estilo del Pierre Menard borgiano, ya que ésta sí es creación, se trata de la copia resignada que acepta el fracaso de la escritura y del conocimiento.

El ideal del joven Flaubert de un estilo que debe ser "rítmico como el verso, preciso como el lenguaje de las ciencias [...] un estilo que penetra la idea como una puñalada con un estilete"13, se desvanece y da lugar a la muy conocida ilusión de escribir un libro sobre nada, sobre un tema cero. Este ideal obedece, no cabe duda, a un proceso dialéctico, el que Gerald L. Bruns resume, en 1970, como "la compulsión por hablar [...] contra la imposibilidad de expresión [...] la cual tan claramente parodia la agonía de Flaubert durante la escritura de Madame Bovary o la impotencia de Mallarmé ante la página en blanco". ${ }^{14}$ Escribir un libro sobre nada, un libro que, de forma exclusiva, surja del estilo, no sólo

${ }^{12}$ Gustave Flaubert, Bouvard et Pécuchet, 1999, París, Le livre de poche, p. 418.

${ }^{13}$ Carta a Louise Colet del 24 de abril de 1852. Qué curiosa la coincidencia fonética entre estilo y estilete, style y stylet.

${ }^{14}$ Gerald L. Bruns, "Silent Orpheus: Annihilating Words and Literary Language", en College English, 31, no. 8, mayo 1970, p. 821-7, aquí p. 825: The compulsion to speak [...] against the impossibility of expression, [...] which so neatly parodies Flaubert's agony during the writing of Madame Bovary, or Mallarmés impotence before the blank page. tiene como consecuencia el trabajo literario desesperado, sino también significa aceptar la tarea literaria como un puro capricho divino-evoco aquí también el océano-organismo de Solaris, la novela de Stanislav Lem. Mallarmé contemplando la página en blanco sabe que, cuando finalmente la convierte en el Coup de dés, va a dejar abierta la oración, prolongando de esta manera la angustia ante lo noadjetivado, a la que Barthes se referiría casi 100 años más tarde. Dejará abierta la posibilidad de mundos infinitos que implica la no-existencia, o por lo menos, la indescriptibilidad de la realidad. Flaubert, cuando reduce a sus héroes a la tarea de copiar copias, cierra la oración, pero indica a la vez que cualquier acto de escribir es inútil, ingenuo y está condenado al fracaso. Probablemente el poeta simbolista Mallarmé y el novelista realista Flaubert generan de esta manera, simultáneamente, el discurso moderno que es arbitrario, sin fundamentos y fácilmente intercambiable, del que este artículo es -quiera su autor o no- un ejemplo.

"El autor es un dios", dice Roland Barthes al final de $S / Z$, "(su lugar de origen es lo significado); el crítico, por su parte, es el sacerdote, atento para poder descifrar la Escritura del dios". ${ }^{15}$ El místico Barthes, el

\footnotetext{
${ }^{15}$ Roland Barthes, $S / Z$, p. 166.
} 
creyente estructuralista, logró finalmente, un siglo después de Flaubert y Mallarmé, desentrañar lo que es, lo que podría ser, la literatura: un juego gigantesco, autorreferencial y metafísicamente impotente, que en miles de años sólo formuló y repitió una y otra vez dos verdaderos postulados ontológicos: 'Yo soy' (la página en blanco de Mallarmé es una de sus formulaciones) y 'conócete a ti mismo' (los pequeños burgueses Bouvard y Pécuchet son representantes destacados de la máxima). La literatura podría ser esto. Nada más, ni nada menos. 